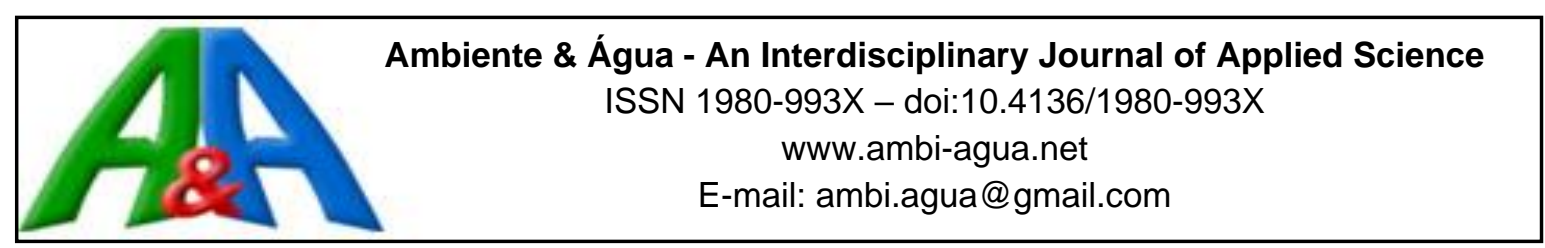

\title{
Simulações de clima futuro no domínio da mata atlântica: transecto Ubatuba, SP e Extrema, MG, Brasil
}

\author{
doi:10.4136/ambi-agua.1894
}

Received: 26 Sep. 2016; Accepted: 29 Oct. 2016

\author{
Valeriam Dias $^{1 *}$; Gilberto Fisch ${ }^{1,2}$; Simey Thury Vieira Fisch ${ }^{1}$ \\ ${ }^{1}$ Universidade de Taubaté (UNITAU), Taubaté, SP, Brasil \\ Programa de Pós-Graduação em Ciências Ambientais \\ ${ }^{2}$ Instituto de Aeronáutica e Espaço (IAE), São José dos Campos, SP, Brasil \\ Departamento de Ciência e Tecnologia Aeroespacial (IAE/DCTA) \\ *Autor correspondente: e-mail: valeriamdias.sts@gmail.com, \\ fisch.gilberto@gmail.com, simey.fisch@gmail.com
}

\section{RESUMO}

Este trabalho possibilitou verificar as diferenças climáticas que ocorrem na área de estudo que vai desde o litoral paulista (Ubatuba/SP) até o sul de Minas Gerais (Extrema/MG), analisando-se ainda os municípios de Taubaté/SP e Campos do Jordão/SP situados ao longo deste transecto. Esta região apresenta topografia complexa, o que colabora para a existência de diferentes tipos de clima e de vegetação. Utilizando-se de dados dos elementos climáticos precipitação e temperatura do ar, analisou-se estatisticamente esta região intensamente transformada pela ocupação humana e pelo desenvolvimento da agropecuária nos últimos séculos. Com base no uso do modelo regional ETA (downscaling) de mesoescala na resolução espacial de 20 x 20 km acoplado ao Modelo Geral de Circulação Atmosfera-Oceano HadCM3; foi possível fazer a projeção do clima para os intervalos de tempo 2011-2040; 2041-2070; 20712099; para o cenário climático A1B do IPCC e compará-los com os dados obtidos do passado (1961-1990). Com base nas análises de dados, verificou- se a ocorrência do aumento do valor médio da temperatura do ar para todos os intervalos de tempo, podendo este a ser superior a $3^{\circ} \mathrm{C}$ até o final desse século. Também deverá haver um aumento no total anual de precipitação nestes três intervalos de tempo, ainda que pequeno, podendo este reduzir-se para o intervalo final (2071-2099). Embora o aumento da temperatura e da precipitação sejam maiores para o mês de janeiro para quase todos os municípios estudados, haverá uma maior variabilidade para o mês de julho, indicando que eventos extremos terão mais chances de ocorrer no período de inverno para quase toda a região.

Palavras-chave: gradiente altitudinal, mudança climática, precipitação, temperatura.

\section{Future climate simulations in the atlantic forest: transect Ubatuba/SP and Extrema/MG}

\section{ABSTRACT}

This article analyzes the climatic differences that occur in a transect that extends from São Paulo State coast to the south of Minas Gerais State, including the municipalities of Ubatuba/SP, Taubaté/SP, Campos do Jordão/SP and Extrema/MG. This territory has a complex topography which contributes to the existence of different types of climate and vegetation. Based on precipitation and temperature data produced by a climate simulation model, it was possible to statistically analyze the future climate of this region heavily transformed by human 
occupation and by the development of agriculture. Using the regional model ETA (downscaling) in the resolution $20 \times 20 \mathrm{~km}$ coupled with the general circulation atmosphereocean model HadCM3, it was possible to forecast the climate scenarios A1B from IPCC for the time intervals 2011-2040; 2041-2070; 2071-2099 and to compare them with historic data (19611990). Based on data analyzes, an increase in the average air temperature was found for each time period observed, reaching more than $3^{\circ} \mathrm{C}$ higher until the end of this century. Also, in general, there will be an increase in the total annual amount of precipitation in these three periods of time, which might be reduced in the last period (2071-2099), especially for Ubatuba/SP. Although the temperature and precipitation increases are higher in January in nearly all the studied cities, there will be a higher variability in July, showing that extreme events are more likely to occur during winter in nearly all regions.

Keywords: altitudinal gradient, climate change, precipitation, temperature.

\section{INTRODUÇÃO}

Atualmente, a humanidade enfrenta um problema ambiental cuja relevância é muito importante para o futuro do planeta e da sociedade. Este afetará todos os seres vivos do planeta, principalmente os países mais pobres que, mesmo não contribuindo significativamente para o aumento nas emissões de gases de efeito estufa, sofrerão as maiores consequências já que possuem uma menor capacidade de adaptação devido a sua estrutura econômica e social fragilizada (PBMC, 2014).

Pela primeira vez na história da humanidade os níveis de CO2 (importante gás de efeito estufa) na atmosfera mundial já superaram a concentração recorde de 400 ppm (NOAA, 2015). Manter esses níveis na atmosfera por um período muito prolongado implica em amplificar os efeitos do aquecimento global (CO2-EARTH, 2016). A preocupação sobre essa questão é imensurável, considerando que antes da Revolução Industrial os níveis de $\mathrm{CO} 2$ na atmosfera eram de 280 ppm, em 1994 passaram para 358 ppm, atingindo 380 ppm em 2006 (McCartney, 2011). Pode-se dizer que antes da Revolução Industrial o ciclo de carbono estava balanceado, pois a quantidade emitida pela atmosfera era praticamente igual ao absorvido pelo solo e oceano. Porém, no último século, a emissão desse gás por veículos automotores, queima de combustíveis fósseis e por queimadas de florestas tropicais decorrentes de ação humana, tem sido responsável pelo aumento dos Gases do Efeito Estufa - GEE (Brasil, 2009).

Criado em 1988, o IPCC (Painel Intergovernamental sobre Mudanças Climáticas) vem reafirmando em seus relatórios a tendência do aumento das concentrações de Gases de Efeito Estufa e reforça que eles são responsáveis pelo aquecimento observado nos últimos 250 anos, sobretudo nas últimas três décadas. Além de deixar claro que a alteração no balanço radiativo da Terra tenderá a mudar as temperaturas atmosféricas e oceânicas, e consequentemente os padrões de circulação da atmosfera, o IPCC, também divulga informações para que mecanismos de adaptação e de mitigação sejam criados a fim de diminuir os impactos ambientais que se tornaram cada vez mais frequentes em todas as regiões do globo, e que estão ampliando os eventos extremos. Em seu último relatório AR5, o IPCC enfatizou a necessidade de uma redução imediata das emissões dos Gases do Efeito Estufa em todas as partes do planeta, a fim de que o aumento da média de temperatura do ar não ultrapasse a $2^{\circ} \mathrm{C}$ até o fim do século, limite a qual os cientistas afirmam que o planeta estaria condenado a um futuro de efeitos devastadores (IPCC, 2014; United Nations, 2015; National Academies of Sciences, 2016).

Prováveis consequências deste aquecimento devem ainda afetar os sistemas físicos, tais como, os recursos hídricos, o nível do mar; o sistema biológico - os ecossistemas naturais e a distribuição de espécies; a sociedade num todo, interferindo na disponibilidade de água, dificuldade no transporte fluvial e principalmente na frequência em desastres naturais (PBMC, 2014; Brasil, 2015). 
Comim e Correa-Macanã (2013) apontam que as mudanças climáticas podem afetar a vida das pessoas mesmo indiretamente, constituindo um risco latente para o retrocesso do desenvolvimento humano, cujos impactos são complexos e múltiplos, pois, mesmo de forma indireta acarretam em: deslocamento da população, interferência no acesso à educação e a segurança ou mesmo na perda de valores culturais e nas relações sociais.

Nesse sentido, as simulações climáticas são uma das ferramentas capazes de fornecer algum tipo de projeção do clima no futuro. Baseiam-se em modelos matemáticos que descrevem as interações de massa de ar da atmosfera e dos fatores e elementos climáticos, podendo indicar possíveis consequências devido o aumento da temperatura do ar na Terra nos diferentes cenários climáticos criados pelo IPCC.

Nas últimas décadas a confiabilidade sobre o uso de modelos climáticos aumentou consideravelmente, fato que ocorreu devido à evolução no entendimento dos processos atmosféricos e na maior capacidade dos computadores processarem e armazenarem informações, bem como no uso de métodos em que se pode melhor representar o sistema climático (Sampaio e Dias, 2014). Porém, embora estes tenham avançado com resoluções espaciais de poucas dezenas de quilômetros ainda não são totalmente capazes de processos em pequena escala que permitam uma simulação explícita dos recursos locais, tais como a topografia, uso da terra, linhas costeiras, vegetação e lagos (Pesquero et al., 2010; Sampaio e Dias, 2014). Assim, para prover simulações de longo prazo das mudanças climáticas com maior resolução, Modelos Climáticos Regionais (MCR) são aninhados aos Modelos Climáticos Globais (MCGA) para fornecer detalhes necessários ao estudo do local (Chou et al., 2014).

Apesar da grande evolução do conhecimento climático e dos inúmeros avanços nos sistemas de observações, na capacidade de assimilação de dados computacionais e no aumento da resolução dos modelos climáticos, ainda existem muitos desafios técnico-científicos pela frente. Questões sobre como melhor representar a dinâmica das interações do clima planetário junto às mudanças do uso da terra e das dimensões humanas; a consideração dos processos do sistema climático na escala espacial e temporal são exemplos que atualmente estão presentes na pauta dos pesquisadores, o que deve contribuir para avanços ainda maiores no campo da ciência climática (Sampaio e Dias, 2014).

Por outro lado, a área de estudo está localizada em uma região de grande importância econômica ao país e que concentra grande urbanização estando suscetível às transformações nela decorrentes. Acompanhada da urbanização, a devastação da Mata Atlântica se tornou cada vez mais acelerada. Segundo Joly e Colombo (2010), no estado de São Paulo, em 2000, existiam somente $13 \%$ restante da mata original, comparada aos $85 \%$ existentes em 1500. Estes remanescentes estão especialmente localizados na Serra do Mar e na Serra da Mantiqueira, que devido à topografia dificulta a ação humana, mas são bastante vulneráveis às mudanças climáticas. Considerando-se que as alterações climáticas podem modificar o domínio fitogeográfico da Mata Atlântica em diferentes gradientes de altitude, faz-se necessário um estudo que avalie os prováveis impactos provocados pelas variações de temperatura e precipitação na região em estudo, compreendendo os municípios de Ubatuba-SP, Taubaté-SP, Campos do Jordão-SP e Extrema-MG. Em um trabalho complementar (Dias, 2016), é discutido como um indicador biológico, no caso as palmeiras tropicais, podem ter afetado seu domínio espacial em função das variações climáticas.

O presente trabalho tem por objetivo analisar as variações dos elementos climáticos de temperatura do ar e precipitação que ocorrem na área de estudo que vai desde Ubatuba-SP, no litoral paulista, à Extrema-MG, localizada ao sul de Minas Gerais. A área teve o clima simulado por um MCR aninhado a um MCGA, nos intervalos de tempo de 1961-1990 (denominado de passado), 2011-2040; 2041-2070 e 2071-2099 (todos esses denominados de futuro), para que se possa compreender as possíveis consequências advindas ou não das variações de temperatura e precipitação.

Rev. Ambient. Água vol. 11 (suplemento) Taubaté, 2016 


\section{MATERIAIS E MÉTODO}

\subsection{Localização e caracterização da área de estudo}

A área de abrangência desse estudo (Figura 1) corresponde aos municípios de Ubatuba, Taubaté e Campos do Jordão, localizados no estado de São Paulo; e o município de Extrema localizado ao sul do estado de Minas Gerais, pertencentes à região sudeste do país (IBGE, 2012).

Apesar dessa região se apresentar intensamente transformada, os principais elementos naturais que caracterizam as paisagens são as formas de relevo denominadas "mares de morros" e os remanescentes de mata tropical, conhecida como Mata Atlântica e Floresta da Mantiqueira. No entanto essa área apresenta aspectos físicos diferenciados, quanto aos fatores geológicos, climáticos, topográficos e fitogeográficos.

Na planície litorânea onde se localiza parte do município de Ubatuba- SP $\left(23^{\circ} 25^{\prime} 55^{\prime \prime} \mathrm{S} \mathrm{e}\right.$ $45^{\circ} 4^{\prime} 58^{\prime}$ ' O), por exemplo, o clima é tropical úmido, cuja pluviosidade anual está em torno de $2.400 \mathrm{~mm}$ e temperatura média de $24^{\circ} \mathrm{C}$, sendo Af segundo a classificação de Köeppen. Formam-se nessas áreas de baixa altitude, os mangues, as planícies marinhas, os terraços marinhos, os cordões arenosos, os campos de dunas e as planícies fluvio lacustre marinha, caracterizada desta forma por ser um ambiente extremamente frágil, conforme analisa Machado (2009). A proximidade dessa planície à Serra do Mar propicia a existência da Mata Atlântica, graças a influência das massas de ar e vapor d'água que ao encontrarem obstáculos nas escarpas se condensam e precipitam, possibilitando à floresta a umidade necessária para o seu desenvolvimento.

Todavia, a região do Vale do Paraíba, onde se situa o município de Taubaté-SP $\left(23^{\circ} 03^{\circ}\right.$ 39" S e 45 37' 30" O, $590 \mathrm{~m}$ de altitude), ter-se-ía originado por um sistema de falhas normais que afetaram as rochas proterozóicas, durante o Terciário Superior. A fossa tectônica por onde corre o rio Paraíba do Sul, parcialmente preenchida por sedimentos lacustres, apresenta folhelhos pirobetuminosos cobertos por arenitos argilosos com lentes de argilas mal estratificadas. Nos folhelhos ocorrem fósseis de peixes, tartarugas, penas de aves e vários crustáceos (Leinz e Amaral, 1975).

Nas altitudes elevadas da Serra da Mantiqueira, localizam-se os municípios de Campos do

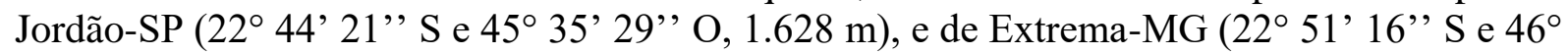
19' 57’ O, 973 m). Apesar de Campos de Jordão-SP não ficar exatamente dentro do transecto, optou-se por incluí-lo em suas análises, pois seu clima é similar ao de Monteiro Lobato (este sim incluído no transecto) e de interesse socioeconômico e ambiental, por ser uma das cidades mais importantes da RMVPLN.

Além da influência da latitude, a topografia também define o clima da região, compreendida por verões suaves, mornos, amenos ou levemente frios, existindo estação seca no inverno e por isso sendo considerada como Cfb segundo a classificação climática Köeppen. Nessa localidade a precipitação anual está entre 1.100 a $2.000 \mathrm{~mm}$ e temperatura média anual entre 15 a $18^{\circ} \mathrm{C}$, sujeita a geadas severas (Alvares et al., 2014). Tanto a Serra da Mantiqueira como a do Mar originaram-se de movimentos tectônicos que permitiram os dobramentos e as falhas. Resultantes de dobramento do escudo cristalino brasileiro e por falhamentos que ocorreram a 70 milhões de anos e que elevaram o relevo, vindo o processo intempérico posteriormente a modelá-lo (Leinz e Amaral, 1975). Na região da Mantiqueira, rochas de granito e metamórficas indicam a formação geológica. As rochas metamórficas antigas quando desgastadas, fazem aflorar as rochas rígidas de granito, trazendo à tona a sua recente chegada. 

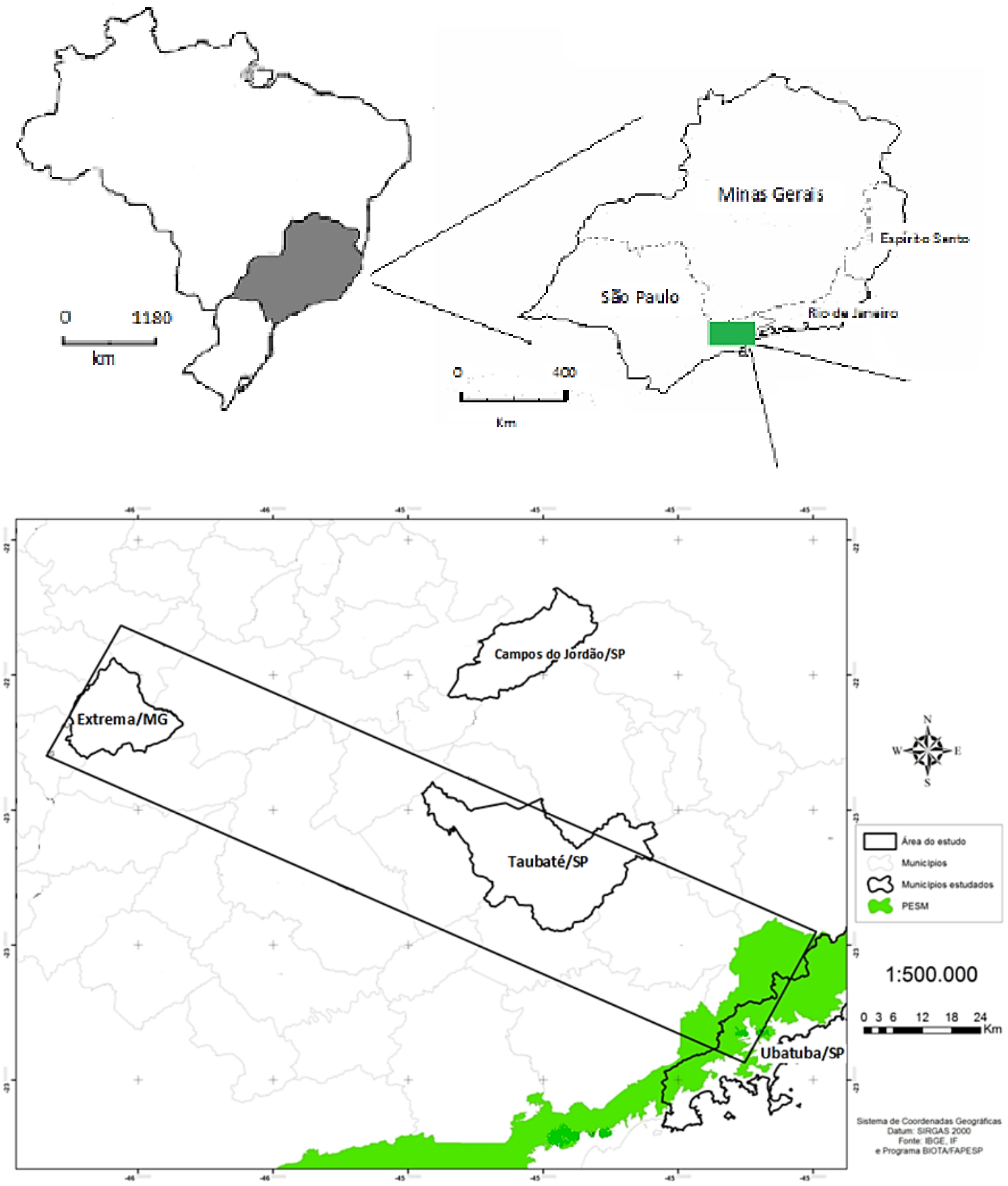

Figura 1. Localização da área de estudo, transecção entre Ubatuba/SP e Extrema/MG.

\subsection{Análise de cenários futuros}

Para a análise do cenário climático futuro utilizou-se dados diários de temperatura do ar e de total de precipitação obtidos pelo modelo ETA/HadCM3 entre os intervalos de tempo 19611990, 2011-2040, 2041-2070 e 2071-2099, que foram fornecidos pelo CPTEC/INPE (Chou et al., 2014).

A compreensão das mudanças climáticas nesta área dependeu de análises de simulação climática das médias anuais de temperatura do ar e de precipitação desse modelo para o cenário A1B do IPCC, que representa um cenário intermediário, pois sugere um mundo com rápido crescimento econômico acompanhado por desenvolvimento tecnológico. Estima-se um menor crescimento populacional, porém os indivíduos ainda procurarão enriquecer-se em detrimento 
da qualidade ambiental. Embora não sejam diretamente comparáveis, o cenário A1B (utilizado até o AR4 do IPCC), equivale ao cenário RCP 4.5 do IPCC AR5, representando um futuro onde a estabilização dos GEE ocorrerá antes de 2.100.

A resolução espacial desse modelo climático foi de $20 \times 20 \mathrm{~km}$, de forma que aumentou a possibilidade de ter com maior exatidão as variáveis de temperatura do ar e da precipitação. A variabilidade dos elementos climáticos temperatura do ar e precipitação foram estudados pelo cálculo do desvio padrão da amostra (quer seja na escala de tempo anual, quer seja sazonal ou mensal). Estes cálculos (desvio-padrão) foram determinados com fórmulas padrões do pacote EXCEL.

Maiores informações sobre os detalhes do modelo utilizado, bem como os dados podem ser encontrados em Santos (2014) e Dias (2016).

\section{RESULTADOS E DISCUSSÃO}

\subsection{Comparação entre os dados de simulação climática passado e futuro - elemento climático temperatura do ar (escalas sazonal e intrasazonal)}

Inicialmente analisou-se o ciclo anual do valor médio da temperatura do ar na escala de tempo mensal, para os municípios de Ubatuba-SP, Taubaté-SP, Campos do Jordão-SP e Extrema-MG e que estão apresentados na Figura 2. De forma geral, os padrões de temperatura do ar mostram um verão (trimestre DJF) quente, com valores maiores e o inverno (trimestre JJA) frio, os valores menores. Tendo em vista o gradiente altitudinal (fator climático altitude), a cidade mais quente é a localidade de Ubatuba-SP, sendo a mais fria o município de Campos do Jordão-SP. As localidades de Taubaté-SP e Extrema-MG possuem valores médios mensais de temperatura muito próximas entre si, sendo a primeira levemente mais quente que a segunda, o que está de acordo com as altitudes dos municípios. Além disso, Taubaté-SP situa-se mais próxima do Oceano, intensificando o fator climático maritimidade.

$\mathrm{O}$ valor médio anual de temperatura do ar para Ubatuba-SP (Figura 2-A) que representa a condição litorânea, variou entre $20,6^{\circ} \mathrm{C}$ para o intervalo de tempo passado, aumentando para $21,9^{\circ} \mathrm{C}$ durante o intervalo de tempo 2011-2040, posteriormente aumentou para $22,8^{\circ} \mathrm{C}$ no intervalo de 2041-2070 e finalizando para um valor limite de $23,7^{\circ} \mathrm{C}$ para o intervalo de tempo 2071-2099. Desta forma, verifica-se uma diferença que atinge $+3,1^{\circ} \mathrm{C}$ entre os dados do passado (também chamado de base-line) e o último intervalo de tempo futuro 2071-2099, caracterizando amplamente o aquecimento da atmosfera.

De forma geral, este comportamento também se verifica nas outras localidades estudadas, a saber: em Taubaté-SP (Figura 2-B), que representa as condições da planície do Vale do Paraíba do Sul, os valores da temperatura aumentaram entre $18,8^{\circ} \mathrm{C}$ para o intervalo de tempo passado, até um valor de $22,4^{\circ} \mathrm{C}$ no intervalo de tempo entre 2071-2099, com uma diferença de $+3,6^{\circ} \mathrm{C}$. Para o caso da Serra da Mantiqueira (lado oriental) representado pela cidade de Campos do Jordão-SP (Figura 2-C), as temperaturas médias aumentaram entre $16,6^{\circ} \mathrm{C}$ no intervalo passado para um valor de $20,3^{\circ} \mathrm{C}$ ao final do século XXI, representando um aumento de $+3,7^{\circ} \mathrm{C}$. Finalmente, para o município de Extrema-MG (Figura 2-D), que representa a vertente ocidental da Serra da Mantiqueira, estes valores aumentaram de $18,3^{\circ} \mathrm{C}$ para $21,9^{\circ} \mathrm{C}$, representando uma variação $+3,6^{\circ} \mathrm{C}$. Em síntese, todas estas localidades tiveram um aumento acentuado da temperatura do ar (em torno de $3,5^{\circ} \mathrm{C}$ ), sendo que Ubatuba-SP apresentou um aquecimento um pouco menor (de $3,1^{\circ} \mathrm{C}$ ), devido a influência do fator climático maritimidade, pois a maior quantidade de vapor d'água presente na atmosfera controla o aquecimento do ar. Ressalta-se também de que os valores médios observados no intervalo de 1961-1990 estão de acordo com a climatologia da região, apresentados em outros trabalhos (por exemplo, IAC (2016) para Ubatuba-SP, Folhes e Fisch (2006) para Taubaté-SP, Diogo e Fisch (2006) para Campos do Jordão-SP). Não foi encontrado nenhum trabalho climatológico para Extrema-MG. 


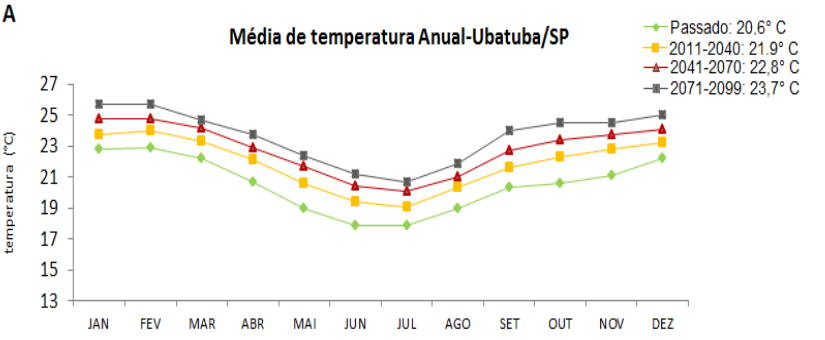

Meses

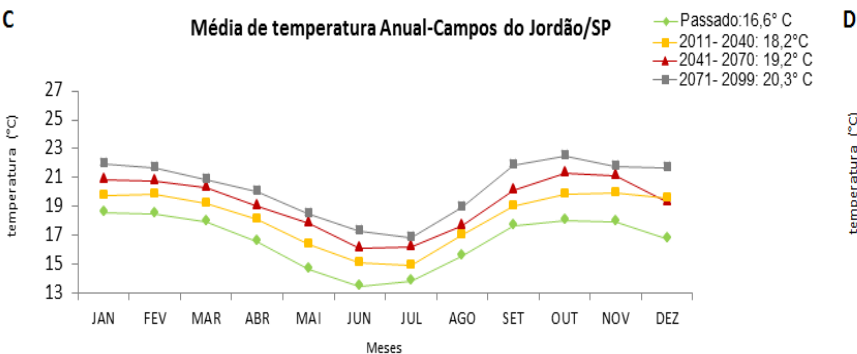

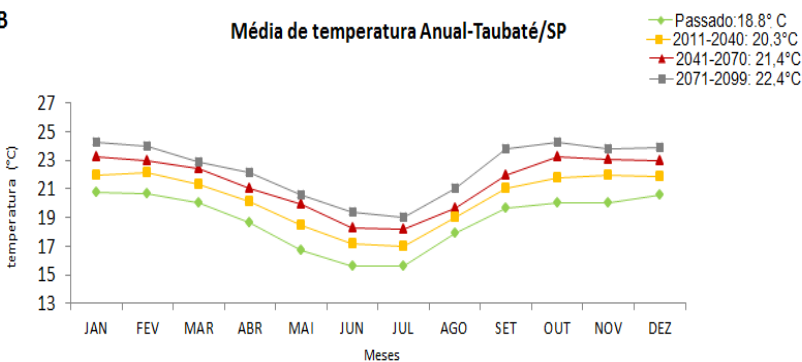

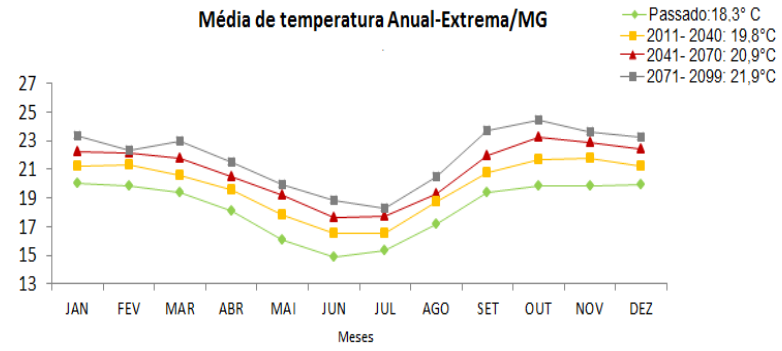

Figura 2. Ciclo Anual da temperatura do ar para diferentes intervalos de tempo para cada município estudado.

Como forma de detalhar as variações na escala de tempo intrasazonal, analisou-se o comportamento da temperatura do ar para os meses de janeiro e julho, que representam meses característicos das estações de verão e inverno, respectivamente (Figuras 3 e 4). Nestas figuras, o eixo horizontal apresenta a sequência de anos (de 1 a 30) para todos os intervalos de tempo. No caso de Ubatuba-SP, observa-se um aumento do valor médio de temperatura para janeiro, desde o intervalo de tempo do passado até o final do século: o primeiro mostra um valor médio de $22,8^{\circ} \mathrm{C}$; enquanto que o último apresenta um valor de $25,7^{\circ} \mathrm{C}$ (Figura $3-\mathrm{A}$ ). Em julho, a temperatura do ar também aumenta, variando de um valor médio de $17,9^{\circ} \mathrm{C}$ para o intervalo passado para um valor de $20,7^{\circ} \mathrm{C}$ para o final do século XXI (Figura 4-A). Estes aumentos são levemente inferiores $\mathrm{a}+3,0^{\circ} \mathrm{C}$, o que leva a supor que as maiores variabilidades estão associadas nos períodos de transição (outono e primavera), pois o aumento do valor da temperatura média anual foi de $+3,1^{\circ} \mathrm{C}$, como mostrado anteriormente. No caso das outras localidades estudadas, observou-se o mesmo padrão, com aumentos da temperatura do ar entre 3,0 e $+3,5^{\circ} \mathrm{C}$, tanto para os meses de janeiro, como de julho. Os meses de julho apresentam um incremento levemente inferior (mas não significativo) do que em janeiro. É interessante observar que a temperatura média de julho em Campos do Jordão-SP será, ao final do século XXI, praticamente de $17^{\circ} \mathrm{C}$, valor este relativamente alto para a germinação e floração de algumas espécies vegetais da região. As outras localidades (Taubaté-SP e Extrema-MG) apresentarão valores superiores a $18^{\circ} \mathrm{C}$, o que é um limite crítico na classificação climática de Köeppen. Em ambos os casos, quer seja para a estação verão, quer seja para o inverno, estes aumentos do valor da temperatura do ar possuem uma tendência de crescimento linear com o tempo. Isto, de certa forma, é de esperar, uma vez que os gases do efeito estufa estão aumentando com o tempo e, consequentemente, a absorção de radiação de ondas longas pela atmosfera. A linha de tendência no intervalo de tempo 2011-2040 é apresentada para todos os casos das Figuras 3 e 4. Para o período de verão, este crescimento linear é mais acentuado do que para o inverno, onde, praticamente, o valor se mantém constante, embora com uma maior variabilidade. 
A

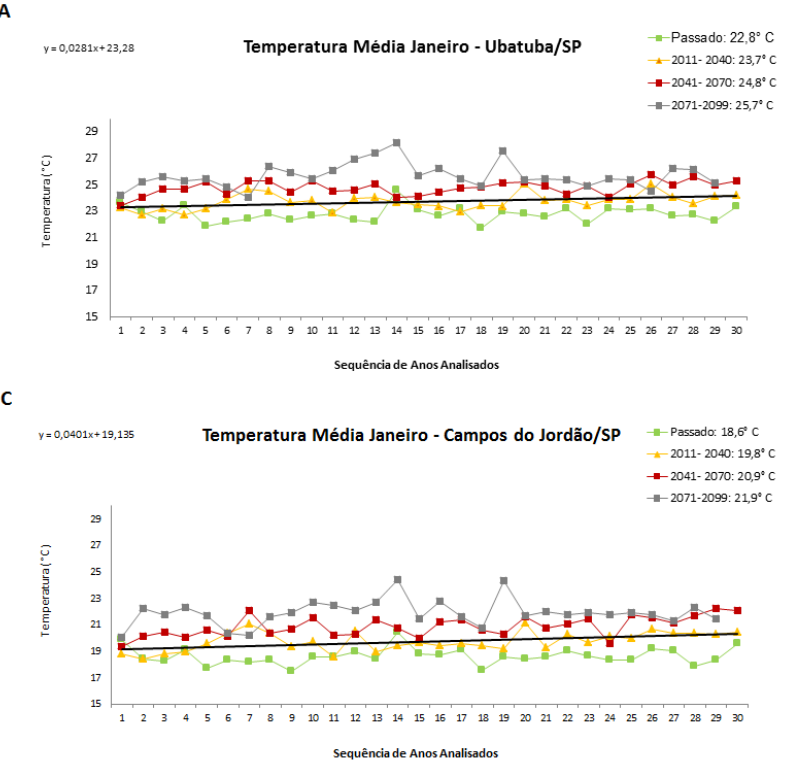

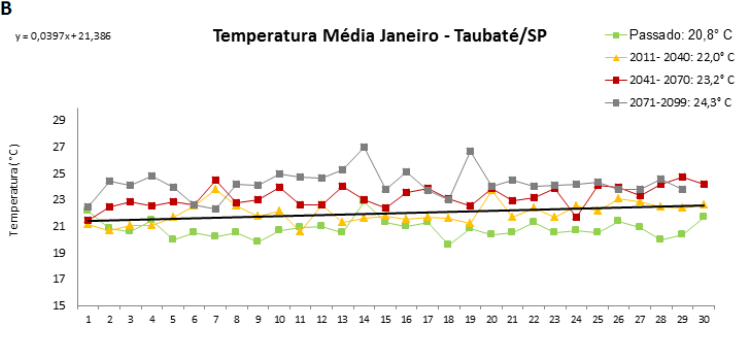

D

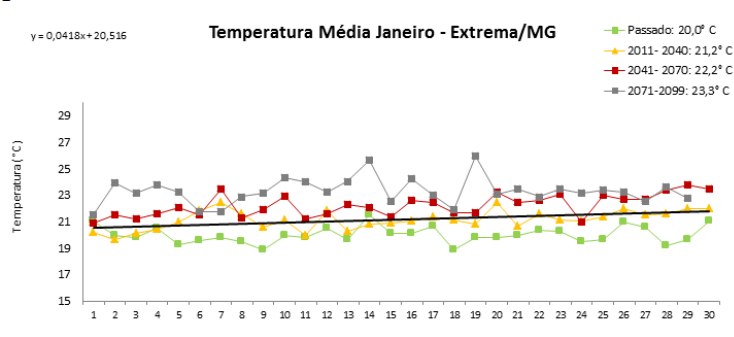

Figura 3. Série temporal da temperatura do ar média referente ao mês de janeiro por intervalo de tempo para os municípios estudados. Linha de tendência para o intervalo 2011-2040.
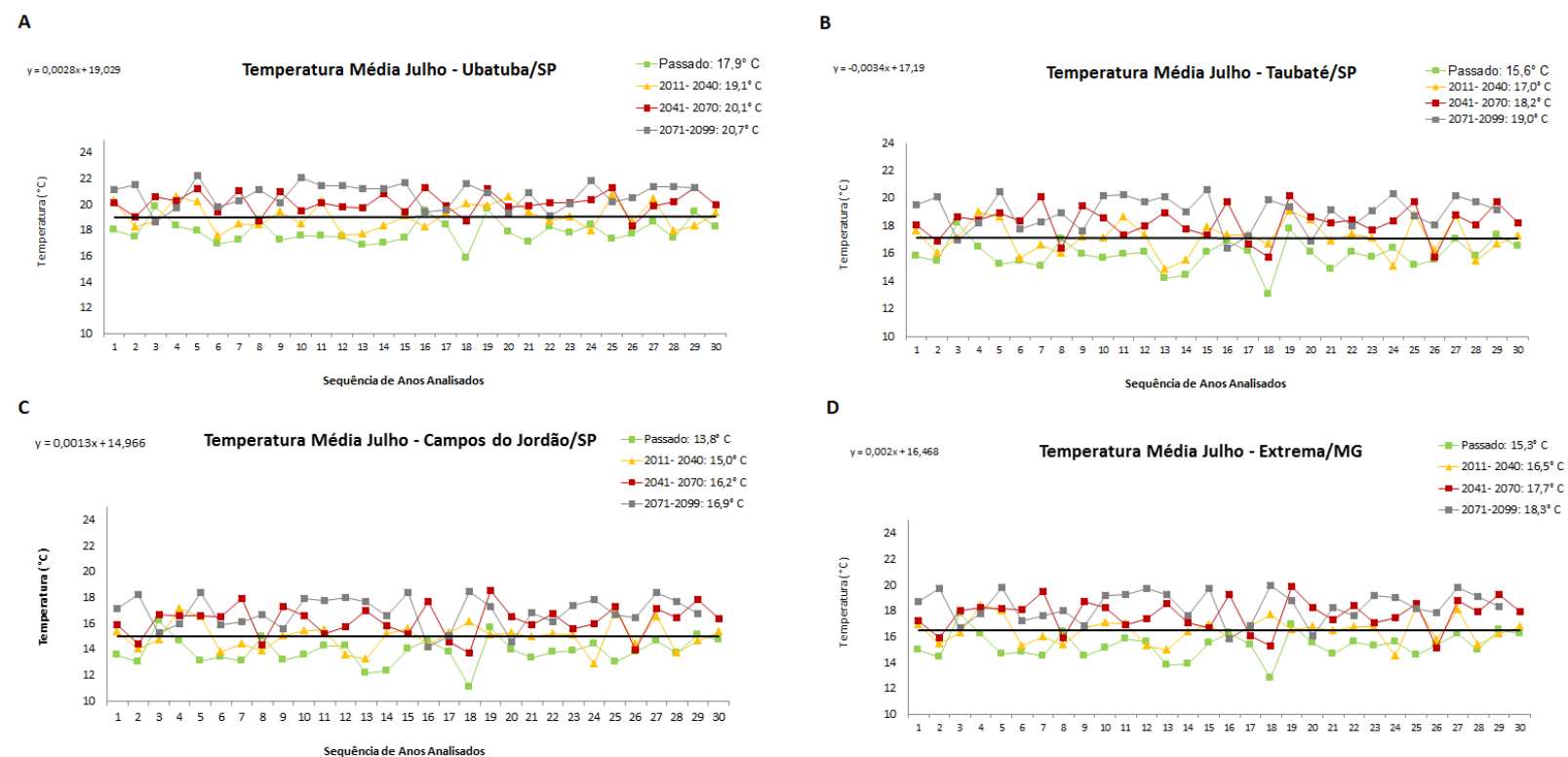

Figura 4. Série temporal da temperatura do ar média referente ao mês de julho por intervalo de tempo para os municípios estudados. Linha de tendência para o intervalo 2011-2040.

\subsection{Comparação entre os dados de simulação climática passado e futuro - elemento climático: precipitação (escalas sazonal e intrasazonal)}

Através dos dados de total de precipitação diária, obtiveram-se os valores totais médios mensais para cada intervalo de tempo para os municípios de Ubatuba-SP, Taubaté-SP, Campos do Jordão-SP e Extrema- MG. A climatologia da região mostra um verão chuvoso e um inverno frio, sendo que esta sazonalidade foi preservada para os três intervalos de tempo da simulação climática. Ao se analisar os dados para o município de Ubatuba-SP, nota-se que haverá um aumento da precipitação no valor médio referente a cada intervalo de tempo analisado. Observase pela Figura 5-A, que a normal climatológica apresenta, para o intervalo de 1961-1990 um valor médio mensal de $167,1 \mathrm{~mm}$ que significa $2.005,2 \mathrm{~mm} /$ ano. Este valor aumentou, sistematicamente, para um valor total mensal de $179,0 \mathrm{~mm}$, que representa $2.148 \mathrm{~mm} /$ ano no 
intervalo de 2011-2040, subsequentemente para um valor total mensal $187,8 \mathrm{~mm}$ ou 2.253,6 mm (intervalo de tempo 2041-2070) apresentando uma pequena redução no valor total mensal para $184,5 \mathrm{~mm}$, ou seja, $2.214 \mathrm{~mm} /$ ano para o último intervalo de tempo.

Da mesma forma que para o elemento climático temperatura do ar, as outras três localidades também apresentaram o mesmo padrão: um aumento do total mensal médio da precipitação, ao longo da simulação climática. Por ser uma localidade próxima ao oceano (fator climático maritimidade), o valor absoluto da precipitação de Ubatuba-SP é superior aos outros três pontos de amostragem, sendo que o município de Campos do Jordão-SP apresentou o menor valor. Neste caso, é o fator climático altitude que está afetando com maior influência. A sazonalidade da precipitação também foi mantida para as três localidades e em todos os intervalos de tempo. Especificamente, a precipitação média em Taubaté-SP é de 158,1 mm (equivale a $1.897,2 \mathrm{~mm} / \mathrm{ano}$ ), aumentando para $179,5 \mathrm{~mm}$ (equivale a $2.154 \mathrm{~mm} / \mathrm{ano}$ ) no último intervalo de tempo (2071-2099). Ocorre um aumento de $+15,7 \mathrm{~mm} / \mathrm{mês}$ para o primeiro intervalo (2011-2040), o que representa um total anual de 188,4 mm. Este valor não é muito, porém representa aproximadamente $14 \%$ do total anual na região, considerado como sendo de 1.350 mm (Fisch, 1999; Oliveira e Galvani, 2015). Para o último intervalo de tempo (20712099), este aumento pode chegar a $+257 \mathrm{~mm}$ por ano, o que não é desprezível, principalmente levando-se em conta a crise hídrica sentida entre os anos de 2014-2016 (Targa e Batista, 2015). Este padrão também se observa para Campos do Jordão-SP, apenas com valores absolutos menores. Também é importante lembrar que estes dois municípios possuem parte de suas Bacias Hidrográficas na calha do Rio Paraíba do Sul.

A localidade de Extrema-MG apresenta o mesmo comportamento das outras duas localidades (Taubaté-SP e Campos do Jordão-SP), exceto pelo fato de sua bacia hidrográfica ser um afluente dos rios Piracicaba, Capivari e Jundiaí-PCJ e, consequentemente, de fundamental importância para a sustentabilidade do Sistema Cantareira. Como nos outros casos, a precipitação aumenta ao longo do tempo, atingindo um valor de precipitação média mensal de 178,8 mm (equivalente a $2.146 \mathrm{~mm} / \mathrm{ano}$ ) no intervalo de tempo 2071-2099, que é de aproximadamente $25 \%$ superior ao valor da normal climatológica.

A
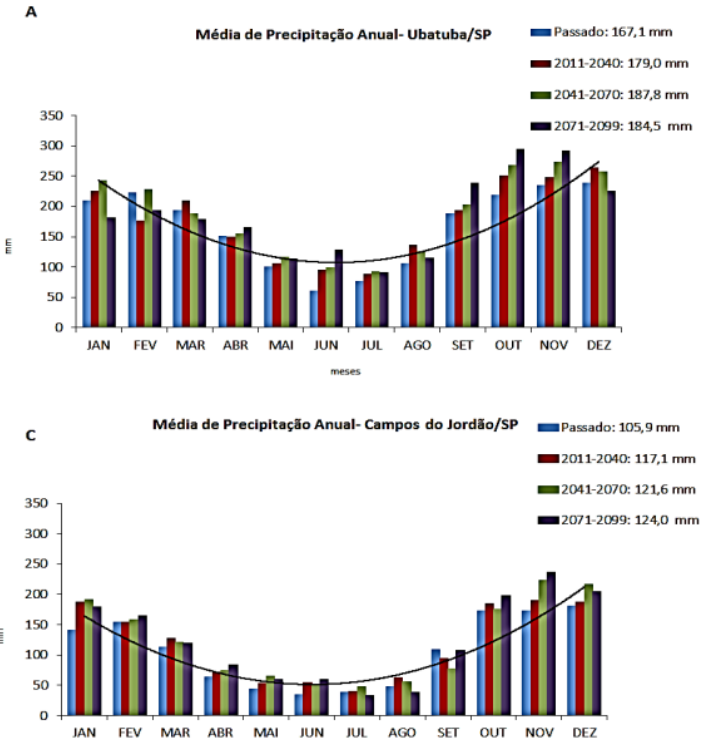
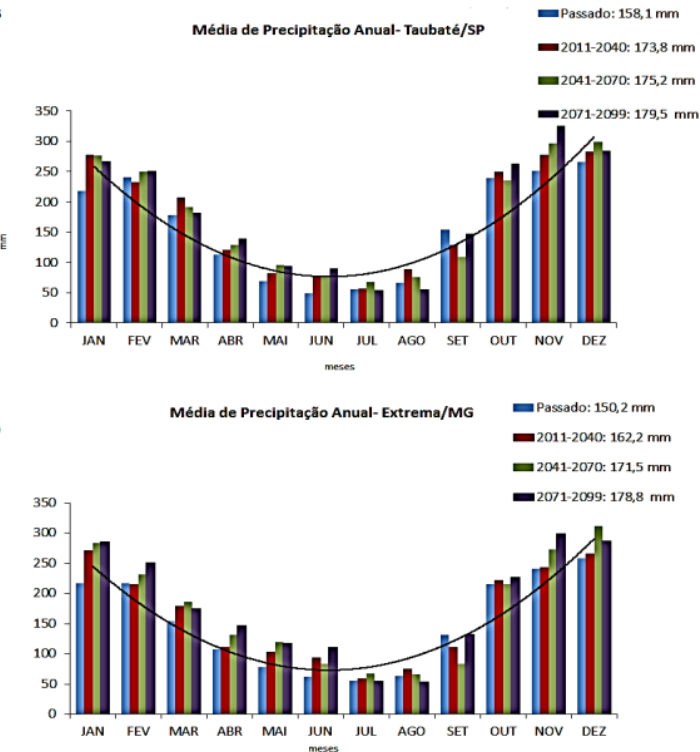

Figura 5. Ciclo sazonal da precipitação, por intervalo de tempo para cada município estudado. Linha de tendência para o intervalo 1961-1990. 
O mês de setembro apresentou uma redução no total de precipitação até o intervalo (20412070) para os municípios de Taubaté-SP, Campos do Jordão-SP e em Extrema-MG. Nessa conjuntura, a estação chuvosa que normalmente ocorre em outubro deverá iniciar-se em novembro, o que poderá contribuir para a ocorrência de chuvas ainda mais acentuadas para esse mês. Para o intervalo final (2071-2099) esses dados de precipitação para setembro devem voltar a se comparar aos do passado muito embora a temperatura continue elevando-se. Para UbatubaSP, a resposta da precipitação frente ao aumento da temperatura parece ter comportamento diferente: a elevação da temperatura poderá contribuir para o aumento das massas úmidas de ar, possibilitando o adiantamento da precipitação para setembro e outubro, meses que se apresentam aumento contínuo de precipitação até o intervalo final (2071-2099).

\subsection{Variabilidade dos elementos climáticos de temperatura do ar e da precipitação}

Como forma de detalhar a variabilidade dos elementos climáticos de temperatura do ar e precipitação, calcularam-se os respectivos desvios padrão dos dados diários para os quatro municípios em questão (Ubatuba-SP, Taubaté-SP, Campos do Jordão-SP e Extrema-MG) em todos os intervalos de tempo. A partir destes resultados e juntamente com as informações já discutidas nos itens 3.1 e 3.2, compararam-se os dados de simulação do clima futuro (intervalos de tempo 2011-2040; 2041-2070; 2071-2099), com os dados do clima passado (1961-1990). Estes resultados estão apresentados nas Figuras 6 e 7, representando os períodos de verão (janeiro) e inverno (julho).

De forma geral, os valores médios de temperatura do ar sempre aumentam, independente da localidade e do intervalo de tempo. Isto já tinha sido observado e discutido no item 3.1. Entretanto, é interessante observar que a variabilidade associada à temperatura também aumenta com os intervalos de tempo, indicando que o clima no final do século XXI estará, além de mais quente, também com uma maior probabilidade de possuir eventos extremos (ondas de calor, geadas, etc). O caso da precipitação é diferente e merece uma análise detalhada. No caso do verão, a localidade de Ubatuba-SP apresenta uma característica toda especial: além das diferenças temporais serem pequenas, esta chega a ser negativa para o último intervalo de tempo. Isto significa que, embora chova mais ao longo do ano (item 3.2), as chuvas no período do verão se reduzirão. No caso das três outras localidades, estas apresentaram uma variação dos totais mensais sempre positiva, embora aproximadamente constante nos intervalos de tempo, sendo em torno de $60 \mathrm{~mm}$ para Taubaté-SP e Extrema-MG e um pouco menor (ao redor de 40 $\mathrm{mm}$ ) para Campos do Jordão-SP. Os desvios padrão também se intensificam com o tempo. Em síntese, esperam-se chuvas mais intensas no verão nestas três localidades, com maior chance de eventos extremos.

Para o mês de julho (Figura 7), a situação é bem diferente. No caso, de Ubatuba-SP, os valores médios mensais são sempre positivos (em torno de $10 \mathrm{~m}$ ), com alta variabilidade no intervalo de tempo 2041-2070. As outras localidades apresentam uma variação no total mensal praticamente nula, com exceção do intervalo de tempo 2041-2070. Embora seja, importante mencionar que estas variações são pequenas, inferiores a $10 \mathrm{~mm}$. Para o último intervalo de tempo (2071-2099), a variação do total mensal é nula ou levemente negativa. A dinâmica das chuvas nessa época do ano é bem peculiar: no caso das localidades montanas (Taubaté-SP, Campos do Jordão-SP e Extrema-MG), as chuvas que ocorrem são de origem frontal. Portanto os resultados mostram que deverá ocorrer uma diminuição da frequência da passagem destas frentes frias ou do contraste térmico das massas de ar, provocando menos chuva. No caso de Ubatuba-SP, além deste fenômeno, a localidade também sofre do efeito da chuva orográfica, que deve provocar um aumento. 
Ubatuba/SP

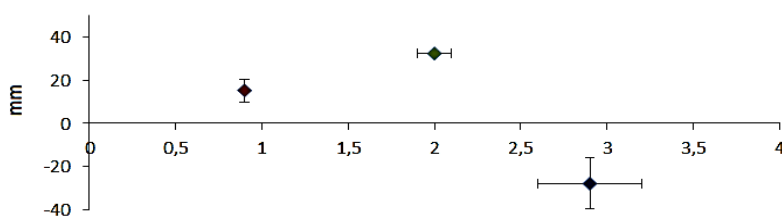

Campos do Jordão/SP

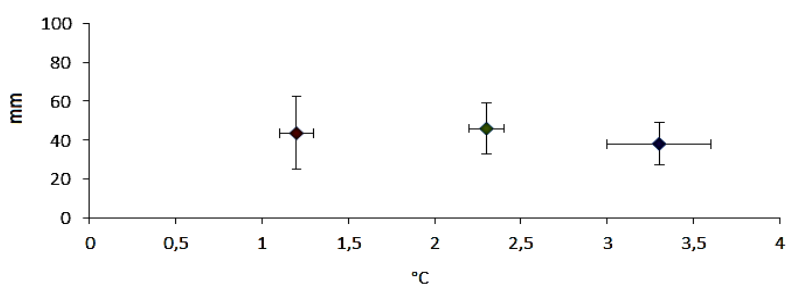

Taubaté/SP

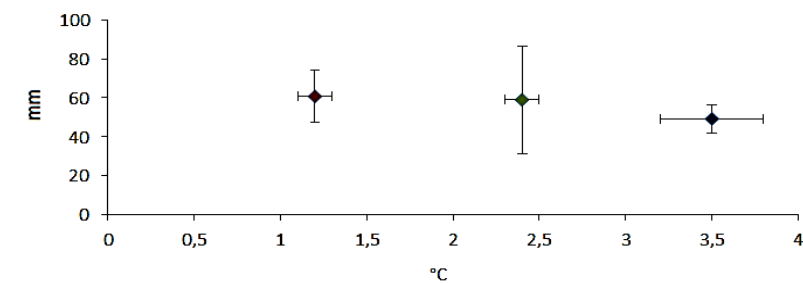
Extrema/MG

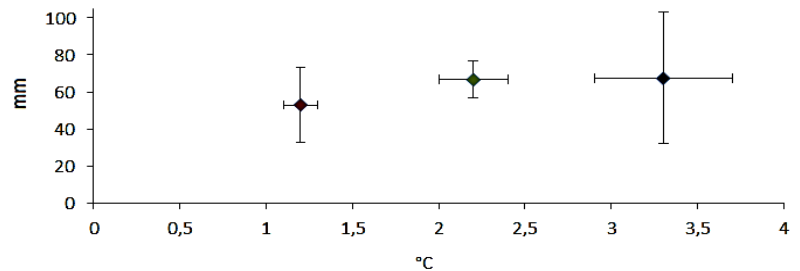

- 2011_2040-1961_1990

2041_2070-1961_1990

- 2071_2099-1961_1990

Figura 6. Variabilidade dos elementos climáticos de temperatura do ar e precipitação para o mês de janeiro referente a cada município analisado. Diferentes cores representam os intervalos de tempo futuro (2011-2040, 2041-2070 e 2071-2099) em comparação com o intervalo de tempo passado (1961-1990) e as barras horizontal e vertical representam os desvios padrão da temperatura e precipitação, respectivamente.

Ubatuba/SP

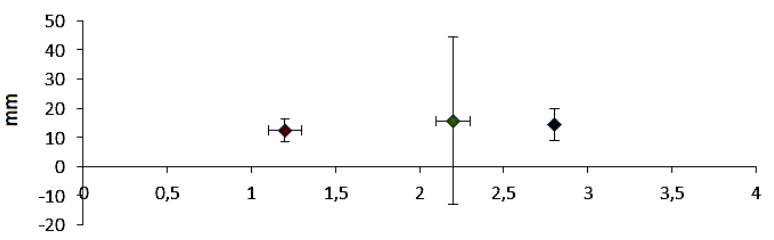

${ }^{\circ} \mathrm{C}$

Campos do Jordão/SP

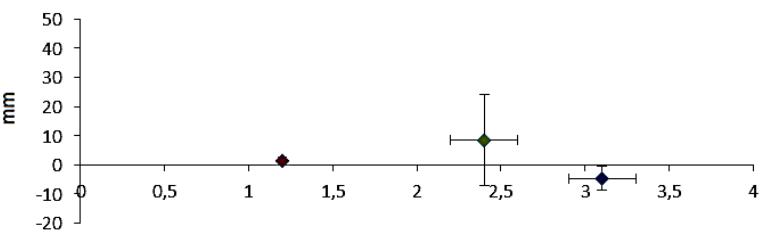

B

Taubaté/SP

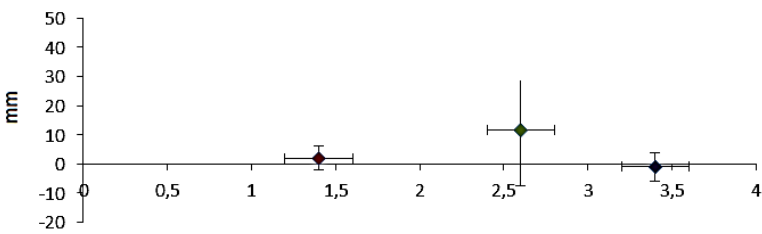

D

Extrema/MG

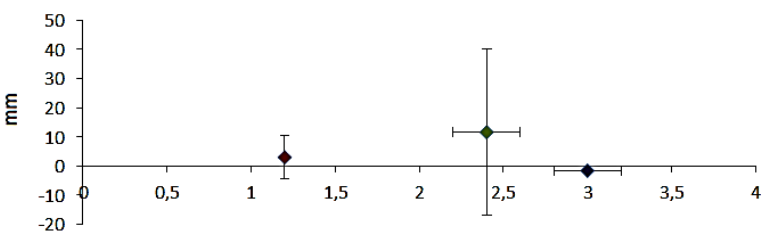

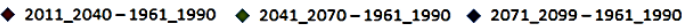

Figura 7. Variabilidade dos elementos climáticos de temperatura do ar e precipitação para o mês de julho referente a cada município analisado. Diferentes cores representam os intervalos de tempo futuro (2011-2040, 2041-2070 e 2071-2099) em comparação com o intervalo de tempo passado (1961-1990) e as barras horizontal e vertical representam os desvios padrão.

Rev. Ambient. Água vol. 11 (suplemento) Taubaté, 2016 


\section{CONCLUSÃO}

A simulação do clima para os municípios Ubatuba-SP, Taubaté-SP, Campos do Jordão-SP e Extrema-MG, mostraram um aumento médio da temperatura do ar para todo o século XXI, podendo no intervalo final (2071-2099) atingir valores entre $+3,1$ a $3,7^{\circ} \mathrm{C}$. A localidade de Campos do Jordão-SP, apesar de sua temperatura ser a menor devido à altitude, teve o maior aumento da temperatura média do ar, ao passo que, em Ubatuba-SP, essa diferença foi menor, devido ao fator maritimidade.

Com relação à distribuição de chuvas ao longo do transecto, poderá ocorrer um aumento da precipitação para todas as localidades, podendo chegar a um incremento entre 180 e 250 $\mathrm{mm} / \mathrm{ano}$. A sazonalidade atual (verões chuvosos e invernos secos), será mantida, sendo possível um adiantamento do início do período chuvoso, principalmente na parte alta (Taubaté-SP, Campos do Jordão-SP e Extrema-MG), mas não em Ubatuba-SP. Isto está associado a uma intensificação dos processos convectivos naquelas localidades. Também foram obtidos resultados que mostram uma maior frequência de eventos extremos, tanto para a temperatura (ondas de calor, geadas, etc.), como para a precipitação.

\section{AGRADECIMENTOS}

Os autores agradecem ao grupo de operações meteorológicas do CPTEC/INPE, pela concessão das informações utilizadas neste trabalho. Em particular ao Mestre Thiago Adriano dos Santos, sem o qual este trabalho não teria sido realizado.

Ao programa BIOTA/FAPESP, em especial ao André Rochelle pela elaboração do mapa da área de estudo.

\section{REFERÊNCIAS}

ALVARES, C. A.; STAPE, J. L; SENTELHAS, P. C; GONÇALVES, J. L. M.; SPAVOREK, G. Köppen's climate classification map for Brazil. Meteorologische Zeitschrift, v. 22, n. $6, \quad$ p. 711-728, 2014. Disponível em: http://www.ingentaconnect.com/content/schweiz/mz/2013/00000022/00000006/art0000 8. Acesso em: de 10 de novembro de 2015.

BRASIL. Ministério de Ciência e Tecnologia. Efeito estufa e a convenção sobre mudança do clima: guia sobre mudanças climáticas. Brasília-DF: MCT, 2009.

BRASIL. Ministério do Meio Ambiente. Plano nacional de adaptação. Brasília, 2015. 370 p. Disponível em: https://goo.gl/2hM9vo. Acesso em: de 28 de julho de 2015.

CHOU, S. C; LYRA, A.; MOURÃO, C.; DERECZYNSKI, C.; PILOTTO, I.; GOMES, J. et al. Evaluation of the ETA simulations nested in the three Global Climate Models. American Journal of Climate Change, n. 3, p. 438-454, 2014. Disponível em: http://dx.doi.org/10.4236/ajcc.2014.35039. Acesso em: de 07 de novembro de 2015.

CO2-EARTH. Atmospheric $\mathbf{C O}_{2}$ Concentrations: Annual $\mathrm{CO}_{2}$. Disponível em: https://www.co2.earth/annual-co2. Acesso em: 02 mar. 2016.

COLOMBO, A. F.; JOLY, C. A. Brazilian Atlantic Forest latu sensu: the most ancient Brazilian Forest, and a biodiversity, is highly threatened by climate change. Brazillian Journal of Biology, v. 70, n. 3, p. 697-708, 2010. http://dx.doi.org/10.1590/S151969842010000400002 
COMIM, F.; CORREA-MACANÃ E. Mudança climática e desenvolvimento humano: uma análise baseada na Abordagem das Capacitações de Amartya Sen. Economia, Sociedade y Território, v. 13, n. 43, p. 577-618, 2013.

DIAS, V. Simulações de clima futuro no Domínio da Mata Atlântica: Transecção Ubatuba/SP E Extrema/MG. 2016. Dissertação (Mestrado em Ciências Ambientais) Departamento de Ciências Agrárias, Universidade de Taubaté, Taubaté, 2016.

DIOGO, S. A.; FISCH, G. As mudanças climáticas em Campos do Jordão e sua relação com a transformação da vocação econômica. Biociências, v. 12, n. 1, p. 19-32, 2006.

FISCH, G. F. Distribuição da precipitação em Taubaté, Vale do Paraíba (SP). Taubaté: Departamento de Ciências Agrárias, Universidade de Taubaté, 1999.

FOLHES, M. T.; FISCH, G. Caracterização climática e estudo de tendências nas séries temporais de temperatura do ar e precipitação em Taubaté (SP). Revista Ambiente \& Água, v. 1, n. 1, p. 61-71, 2006. http://dx.doi.org/10.1590/S1519-69842010000400002

INSTITUTO AGRONÔMICO DE CAMPINHAS - IAC. Registro de dados climáticos do Instituto Agronômico. Disponível em: http://www.ciiagro.sp.gov.br/. Acesso em: 10 jul. 2016.

INSTITUTO BRASILEIRO DE GEOGRAFIA E ESTATÍSTICA - IBGE. Brasil em números - Brazil in figures. Brasília, 2012. Disponível em: https://goo.gl/M5jHA. Acesso em: 12 jul. 2014.

PAINEL INTERGOVERNAMENTAL SOBRE MUDANÇAS CLIMÁTICAS - IPCC Mudança do Clima - 2013: A base das ciências físicas. Estocolmo, 2014.

LEINZ, V.; AMARAL, S. E. Geologia geral. 6. ed. São Paulo: Nacional, 1975. 360 p.

MACHADO, M. A. Mudanças climáticas globais, um estudo de caso da variação da temperatura do ar e seus impactos no município de Ubatuba, litoral norte de São Paulo. 2009. Dissertação (Mestrado em Ciências Ambientais) - Departamento de Ciências Agrárias, Universidade de Taubaté, Taubaté, 2009.

MCCARTNEY, A. Ahead of the Curve: scientist's work links fossil fuels, carbon emissions.Erie Times-News, 2011. Disponível em: https://goo.gl/YK2cFr. Acesso em: 10 jun. 2014.

NATIONAL ACADEMIES OF SCIENCES. Attibution of extreme weather events in the context of climate change.Washington, DC: The National Academies Press, 2016. 200 p.

NATIONAL OCEANIC AND ATMOSPHERIC ADMINISTRATION - NOAA. Greenhouse gas benchmark reached 2015. Disponível em: https://goo.gl/YTpYUu Acesso em: 15 maio 2015.

OLIVEIRA, M. R. P.; GALVANI, E. Avaliação do efeito orográfico das precipitações no perfil longitudinal Paraty (RJ) e Campos do Jordão (SP). Entre Lugar, v. 6, n. 11, p. 133-151, 2015 . 
PAINEL BRASILEIRO SOBRE MUDANÇAS CLIMÁTICAS - PBMC. Base científica das mudanças climáticas: contribuição do grupo de trabalho 1 ao primeiro relatório de avaliação nacional do Painel Brasileiro de Mudanças Climáticas. Sumário Executivo GT1. Rio de Janeiro, 2014. 464 p.

PESQUERO, J. F.; CHOU, S. C.; NOBRE, C. A.; MARENGO, J. A. Climate downscaling over South America for 1961-1970 using the ETA Model. Theoretical and Applied Climatology, v. 99, n. 1, p. 75-93, 2010.

SAMPAIO, G.; DIAS, P.L.S. Evolução dos Modelos Climáticos e de Previsão de Tempo e Clima. Revista USP, n. 103, p. 41-54, 2014.

SANTOS, T. A. Análise de precipitação e temperatura: futuros cenários no Município de Taubaté-SP. 2014. Dissertação (Mestrado em Ciências Ambientais) - Departamento de Ciências Agrárias, Universidade de Taubaté, Taubaté, 2014.

TARGA, M. S.; BATISTA, G. T. Benefits and legacy of the water crisis in Brazil. Revista Ambiente \& Água, v. 10, n. 2, 2015. http://dx.doi.org/10.4136/ambi-agua.1629

UNITED NATIONS. Framework convention on climate change. 2015. Disponível em: http://unfccc.int/resource/docs/2015/cop21/eng/109r01.pdf. Acesso em: 18 dez. 2015. 